\title{
Seasonal effects: Evidence from emerging African stock markets
}

\author{
C. Mlambo* \\ Graduate School of Business, University of Stellenbosch \\ PO Box 610, Bellville 7535, Republic of South Africa \\ bws1@maties.sun.ac.za \\ N. Biekpe \\ Africa Centre for Investment Analysis \\ Graduate School of Business, University of Stellenbosch, \\ PO Box 610, Bellville 7535, Republic of South Africa
}

Received June 2006

\begin{abstract}
The paper investigates seasonal effects in seventeen indices on nine African stock markets using regression analysis and the Kruskal-Wallis and Chi-square Median tests. Significant seasonal effects are found on some, but not all indices. The strongest effect observed is the month-of-the-year effect followed by the day-of-the-week effect. The West African Regional stock Exchange (BRVM) exhibited a reversed 'December decline - January rise' pattern, while the turn-of-themonth effect observed for Egypt disappeared after the turn-of-the-year effect was removed. Using the Kruskal-Wallis test, no seasonal effects for Namibia were found. For the other markets, at least one seasonal effect was observed, suggesting some exploitable trading opportunities.
\end{abstract}

*To whom all correspondence should be addressed.

\section{Introduction}

Seasonal anomalies are the greatest challenge to the Efficient Market Hypothesis (EMH). Anomalies are basically irregularities or inconsistencies that conflict with the whole idea that security prices behave in a random manner. It is also hypothesised that any predictable opportunity for abnormal returns, once made public, will be arbitraged away into non-existence. However, some seasonal effects have been in existence for a number of decades. These seasonal effects include the weekend effect identified by Fields (1931), the holiday effect (Fields, 1934) and the turn-of-the-year/January effect (Wachtel, 1942).

While seasonal patterns in stock returns have been documented in the United States and other markets around the world, in Africa, to our knowledge, only the Johannesburg Securities Exchange (JSE) has received significant attention, compared to the other African stock markets. Studies on the JSE include Bhana (1985) who found significantly negative average returns for Mondays and the highest positive returns on Wednesdays for shares traded on the JSE for the period 1978 to 1983. Davidson and Meyer (1993) found that the Monday effect was no longer significant on the JSE using the All Share Index for the period 1986 to 1991. Bhana (1994) found mean pre-holiday returns to be much higher than for the other days on the JSE for the period 1957 to 1990. Bradfield (1990) found significant July and December month-of-the-year effects for the period January 1974 to December 1984. Watson and Smit (1994) found at least one significant seasonal effect on each of the South African share market indices they studied for the period 4 January 1988 to 20 April 1993.

The latest evidence on the JSE, to our knowledge, is from Roux and Smit (2001) who examined if some seasonal patterns still exist on the JSE using the All Share Index, the All Gold Index and the Financial Index. By comparing two periods 1978 to 1989 and 1990 to 1998, they found that most of these anomalies no longer exist on the South African share market.

For other African stock markets, Ayadi, Dufrene and Chatterjee (1998) investigated the January effect on the equity markets of Nigeria, Zimbabwe and Ghana for the periods 1984 to 1995, 1987 to 1995 and 1991 to 1996, respectively. The results showed no January effect in the stock markets of Nigeria and Zimbabwe. For Ghana, the results from the Friedman test showed that the January average return was significantly higher than the average returns of February and May and significantly lower than the average returns of June, August, October and December.

Given the little research on seasonal anomalies on the emerging African stock markets, this paper examines the existence of seasonal patterns on selected African stock markets. These markets include Botswana, the BRVM, Egypt, Ghana, Mauritius, Morocco, Namibia, Tunisia and Zimbabwe. 


\section{Data and Methodology}

The paper uses continuously compounded returns computed from daily closing price indices from nine African stock markets. The data for these indices was obtained from the respective stock exchanges. The periods of analyses range from 4 years 3 months (September 1998 to December 2002) for the West African Regional Exchange (Bourse Regionale des Valeurs Mobilieres) - abbreviated BRVM - in Cote d'Ivoire to 6 years (January 1997 to December 2002) for Egypt, Morocco and Zimbabwe. All the markets covered were trading daily at the end of the period except Ghana, which was trading only three times a week. For the BRVM, although the period covered begins at inception, the market only shifted to daily trading beginning November 2001. The same applies for Mauritius, which shifted to daily trading beginning November 1997. However, unlike for the BRVM, most of the data for Mauritius came from the period of daily trading. While Ghana was excluded from the day-of-theweek/weekend analysis, the BRVM and Mauritius were only analysed for the respective periods of daily trading.

Table 1 reports the descriptive statistics for the calculated daily returns. The number of data points (returns) ranges from 753 for Ghana to 1499 for Zimbabwe. The mean returns were positive for all the indices except Namibia's Local Index, the BRVM and Egypt.

Table 1: General and Descriptive Statistics for the Index Returns

\begin{tabular}{|c|c|c|c|c|c|c|c|c|}
\hline \multirow{3}{*}{$\begin{array}{c}\text { Stock } \\
\text { market }\end{array}$} & \multirow[b]{3}{*}{ Stock Index } & \multirow{2}{*}{\multicolumn{6}{|c|}{$\begin{array}{c}\text { (a) } \\
\text { Descriptive Statistics }\end{array}$}} & \multirow{3}{*}{$\begin{array}{c}\text { (b) } \\
\text { Period Investigated }\end{array}$} \\
\hline & & & & & & & & \\
\hline & & \# Obs. & Mean (\%) & SD (\%) & Skewness & Kurtosis & K-S* & \\
\hline \multirow{3}{*}{ Botswana } & Domestic & 1177 & 0,098 & 0,622 & 2,270 & 16,569 & $6,940 * *$ & \multirow{3}{*}{ 23-Mar-98 to 31-Dec-02 } \\
\hline & Foreign & 1177 & 0,044 & 2,547 & $-1,447$ & 25,919 & $11,053 * *$ & \\
\hline & All & 1177 & 0,049 & 2,403 & $-1,421$ & 25,979 & $10,978 * *$ & \\
\hline \multirow[t]{2}{*}{ BRVM } & BRVM-10 & 752 & $-0,027$ & 0,970 & $-0,750$ & 6,122 & $4,139 * *$ & \multirow{2}{*}{ 16-Sep-98 to 31-Dec-02 } \\
\hline & BRVM-C & 752 & $-0,040$ & 0,692 & $-0,158$ & 5,225 & $3,292 * *$ & \\
\hline \multirow[t]{2}{*}{ Egypt } & HFI & 1489 & $-0,047$ & 1,317 & 0,160 & 1,158 & $2,806 * *$ & \multirow{2}{*}{ 02-Jan-97 to 31-Dec-02 } \\
\hline & EFGI & 1489 & $-0,047$ & 1,398 & 0,106 & 1,085 & $2,616 * *$ & \\
\hline Ghana & GSE & 753 & 0,133 & 1,251 & 2,506 & 39,098 & $6,733 * *$ & 02-Jan-98 to 30-Dec-02 \\
\hline \multirow[t]{2}{*}{ Mauritius } & SEMDEX & 1401 & 0,009 & 0,441 & 0,703 & 8,692 & $3,396 * *$ & \multirow{2}{*}{ 06-Jan-97 to 31-Dec-02 } \\
\hline & SEMTRI & 1401 & 0,037 & 0,441 & 0,756 & 8,815 & $3,563 * *$ & \\
\hline Morocco** & CFG25 & 1493 & 0,002 & 0,634 & 0,821 & 8,327 & $3,892 * *$ & 02-Jan-97 to 31-Dec-02 \\
\hline \multirow[t]{2}{*}{ Namibia } & Overall & 1459 & 0,022 & 2,219 & $-1,542$ & 111,866 & $7,019 * *$ & \multirow{2}{*}{ 06-Jan-97 to 31-Dec-02 } \\
\hline & Local & 1459 & $-0,081$ & 2,130 & $-0,820$ & 145,739 & $10,988 * *$ & \\
\hline \multirow[t]{2}{*}{ Tunisia } & BVMT & 1249 & 0,043 & 0,858 & 0,154 & 1,541 & $3,226 * *$ & \multirow{2}{*}{ 02-Jan-98 to 31-Dec-02 } \\
\hline & TUNINDEX & 1249 & 0,009 & 0,535 & 1,017 & 12,617 & $3,231 * *$ & \\
\hline \multirow[t]{2}{*}{ Zimbabwe } & Industrial & 1499 & 0,164 & 1,741 & $-0,581$ & 12,973 & $4,575 * *$ & \multirow{2}{*}{ 02-Jan-97 to 31-Dec-02 } \\
\hline & Mining & 1499 & 0,118 & 3,165 & $-0,335$ & 11,627 & $6,716 * *$ & \\
\hline
\end{tabular}

* All Kolmogorov-Smirnov Z-statistics are significant at less than the $1 \%$ level suggesting a strong rejection of the normality assumption

**For Morocco only one index was used in the analysis, the CFG25. This is because the MASI and MADEX are fairly new and data for the no-longer-existent IGB could not be obtained.

The mean and standard deviation statistics were multiplied by 100 to give a percentage return since in their numerical values, the mean figures were almost identically zero when rounded to decimal 3.

Table 1 also shows that the returns for all the indices are mostly skewed and have excess kurtosis. The KolmogorovSmirnov test statistics also suggest a rejection of the normality assumption (at the $1 \%$ level of significance) for all the indices in the 9 countries. However, since the regression analysis used here is on 'dummy' variables, a manipulation of the coefficients will give the mean daily returns, and thus enable a descriptive interpretation of the results. The results are substantiated with those from the nonparametric Kruskal-Wallis test.

\section{Regression results}

\section{Day-of-the-week/Monday effect}

The day-of-the-week (DOW) effect suggests that Mondays provide the lowest mean daily returns and Fridays the highest. The weekend effect, therefore, implies a tendency for higher Friday and lower Monday mean daily returns. To examine the DOW effect using regression analysis, the following model is estimated:

$$
R_{t}=\beta_{1}+\beta_{2} \text { Tue }_{t}+\beta_{3} \text { Wed }_{t}+\beta_{4} \text { Thu }_{t}+\beta_{5} \text { Fri }_{t}+\varepsilon_{t}
$$

where $R_{t}$ is the return on day $t$, the constant $\beta_{1}$ represent the Monday mean daily return, $\beta_{2}, \beta_{3}, \beta_{4}$ and $\beta_{5}$ are the response coefficients for the dummy variables $T u e_{t}$, Wed $_{t}$, Thu $u_{t}$ and $\mathrm{Fri}_{t}$, respectively. The dummy variable Tue $_{t}$ takes the value of 1 on Tuesdays and 0 otherwise, Wed takes the value of 1 on Wednesdays and 0 otherwise, and similarly for $\mathrm{Thu}_{t}$ and $\mathrm{Fri}_{t}$. The mean daily returns for Tuesday, Wednesday, Thursday and Friday will be equal to the values of the coefficients for the respective days plus the intercept or Monday mean daily return. The null 
hypothesis is that there are no differences between mean returns for each day of the week. The results of the regression model are presented in Panel (a) of Table 2.

To further examine the Monday effect, which suggests that Monday mean daily returns are lowest and/or more negative than returns for all the other days of the week, equation (1) is simplified by using only one dummy variable, taking the value of 1 on Mondays and 0 otherwise. The following regression model is estimated:

$$
R_{t}=\alpha_{0}+\alpha_{1} \text { Mon }_{t}+e_{t}
$$

where the constant $\alpha_{0}$ represent returns for all the other days of the week, except Monday, and $\alpha_{1}$ is the response coefficient for the dummy variable Mon $_{t}$ that takes the value of 1 on Mondays and 0 otherwise. The results for this regression equation are presented in Panel (b) of Table 2.

\section{Table 2: Regression results for Day-of-the-Week/Monday Effect}

\begin{tabular}{|c|c|c|c|c|c|c|c|c|c|c|c|}
\hline \multirow{2}{*}{$\begin{array}{c}\text { Stock } \\
\text { Exchange } \\
\end{array}$} & \multirow[b]{2}{*}{ Index } & \multicolumn{7}{|c|}{ (a) } & \multicolumn{3}{|c|}{ (b) } \\
\hline & & & $(\mathrm{C}=\mathrm{MON})$ & TUE & WED & THU & FRI & F-stat & $(\mathrm{C}=\mathrm{ROW})$ & MON & F-stat \\
\hline \multirow[t]{6}{*}{ Botswana } & Domestic & coef (\%) & 0,045 & 0,097 & 0,106 & $-0,018$ & 0,079 & 2,033 & $0,110^{* *}$ & $-0,066$ & 2,060 \\
\hline & & t-stat & 1,090 & 1,687 & 1,839 & $-0,315$ & 1,369 & & 5,468 & $-1,435$ & \\
\hline & Foreign & coef $(\%)$ & $-0,330 *$ & 0,358 & $0,556 *$ & 0,278 & $0,673^{* *}$ & $2,440^{*}$ & 0,135 & $-0,465 *$ & $6,171^{*}$ \\
\hline & & t-stat & $-1,966$ & 1,522 & 2,368 & 1,183 & 2,844 & & 1,632 & $-2,484$ & \\
\hline & All Companies & coef $(\%)$ & $-0,307$ & 0,340 & $0,530 *$ & 0,258 & $0,648^{* *}$ & $2,542 *$ & 0,135 & $-0,443^{*}$ & $6,284 *$ \\
\hline & & $t$-stat & $-1,941$ & 1,529 & 2,393 & 1,167 & 2,902 & & 1,736 & $-2,507$ & \\
\hline \multirow[t]{4}{*}{ BRVM } & BRVM-10 & coef $(\%)$ & 0,069 & 0,063 & 0,019 & $-0,189$ & 0,014 & 0,656 & 0,045 & 0,024 & 0,030 \\
\hline & & $t$-stat & 0,569 & 0,370 & 0,111 & $-1,102$ & 0,082 & & 0,742 & 0,174 & \\
\hline & BRVM-Comp & coef $(\%)$ & 0,069 & $-0,029$ & $-0,001$ & $-0,125$ & $-0,016$ & 0,404 & 0,026 & 0,043 & 0,225 \\
\hline & & t-stat & 0,842 & $-0,248$ & $-0,008$ & $-1,080$ & $-0,138$ & & 0,620 & 0,474 & \\
\hline \multirow[t]{4}{*}{ Egypt $^{\#}$} & HFI & coef (\%) & $-0,087$ & 0,052 & $-0,059$ & 0,068 & $\mathbf{0 , 1 3 7}$ & 0,934 & $-0,037$ & $-0,049$ & 0,333 \\
\hline & & $t$-stat & $-1,133$ & 0,479 & $-0,544$ & 0,630 & 1,267 & & $-0,981$ & $-0,577$ & \\
\hline & EFGI & coef $(\%)$ & $-0,111$ & 0,130 & $-0,071$ & 0,104 & 0,158 & 1,415 & $-0,032$ & $-0,079$ & 0,767 \\
\hline & & t-stat & $-1,369$ & 1,124 & $-0,620$ & 0,909 & 1,376 & & $-0,782$ & $-0,876$ & \\
\hline \multirow[t]{4}{*}{ Mauritius } & SEMDEX & coef (\%) & $-0,004$ & $-0,010$ & 0,008 & $-0,012$ & 0,039 & 0,588 & 0,003 & $-0,006$ & 0,042 \\
\hline & & t-stat & $-0,135$ & $-0,256$ & 0,217 & $-0,329$ & 1,018 & & 0,186 & $-0,205$ & \\
\hline & SEMTRI & coef $(\%)$ & 0,029 & $-0,019$ & 0,000 & $-0,011$ & 0,035 & 0,587 & $0,030^{*}$ & $-0,002$ & 0,003 \\
\hline & & t-stat & 1,071 & $-0,492$ & 0,012 & $-0,279$ & 0,925 & & 2,263 & $-0,052$ & \\
\hline \multirow[t]{2}{*}{ Morocco } & CFG25 & coef $(\%)$ & $-0,067$ & $-0,018$ & $0,103 *$ & $0,158^{* *}$ & $0,103 *$ & $4,214^{* * *}$ & 0,020 & $-0,087^{*}$ & $4,546 *$ \\
\hline & & $t$-stat & $-1,836$ & $-0,345$ & 1,996 & 3,063 & 1,999 & & 1,089 & $-2,132$ & \\
\hline \multirow[t]{4}{*}{ Namibia } & Overall & coef $(\%)$ & $-0,015$ & 0,013 & 0,277 & $-0,193$ & 0,083 & 1,710 & 0,027 & $-0,025$ & 0,029 \\
\hline & & $t$-stat & $-0,116$ & 0,073 & 1,511 & $-1,051$ & 0,449 & & 0,410 & $-0,171$ & \\
\hline & Local & coef $(\%)$ & $-0,057$ & $-0,096$ & 0,056 & 0,014 & $-0,095$ & 0,302 & $-0,088$ & 0,035 & 0,060 \\
\hline & & t-stat & $-0,457$ & $-0,546$ & 0,319 & 0,081 & $-0,535$ & & $-1,413$ & 0,246 & \\
\hline \multirow[t]{4}{*}{ Tunisia } & BVMT & coef $(\%)$ & 0,030 & $-0,043$ & 0,070 & 0,045 & $-0,007$ & 0,678 & 0,047 & $-0,016$ & 0,072 \\
\hline & & t-stat & 0,561 & $-0,566$ & 0,913 & 0,581 & $-0,091$ & & 1,717 & $-0,268$ & \\
\hline & TUNINDEX & coef (\%) & 0,032 & $-0,067$ & $-0,033$ & 0,016 & $-0,032$ & 0,909 & 0,004 & 0,029 & 0,584 \\
\hline & & $t$-stat & 0,959 & $-1,397$ & $-0,687$ & 0,340 & $-0,672$ & & 0,207 & 0,765 & \\
\hline \multirow[t]{4}{*}{ Zimbabwe } & Industrial & coef (\%) & 0,031 & 0,136 & 0,182 & 0,165 & 0,177 & 0,558 & $0,196 * *$ & $-0,165$ & 2,110 \\
\hline & & t-stat & 0,308 & 0,951 & 1,277 & 1,154 & 1,229 & & 3,918 & $-1,452$ & \\
\hline & Mining & coef (\%) & $-0,072$ & 0,144 & 0,289 & 0,039 & 0,478 & 1,140 & 0,164 & $-0,236$ & 1,305 \\
\hline & & t-stat & $-0,388$ & 0,553 & 1,116 & 0,149 & 1,830 & & 1,800 & $-1,142$ & \\
\hline
\end{tabular}

Panel (a) and panel (b) present the regression results, that is, the regression coefficients, $\mathrm{t}$ and $\mathrm{F}$ statistics for the following equations, respectively:

$R_{t}=\beta_{1}+\beta_{2}$ Tue $_{t}+\beta_{3}$ Wed $_{t}+\beta_{4}$ Thu $t+\beta_{5}$ Fri $_{t}+\varepsilon_{t}$

$R_{t}=\alpha_{0}+\alpha_{1}$ Mon $_{t}+e_{t}$

All coefficients have been presented as percentages (multiplied by 100) since most of them became almost zero after rounding to decimal 3 . This could have been avoided from the outset by calculating rates of return as percentages rather than as fractions.

** and * imply statistical significance for a two-tailed test at the $1 \%$ and $5 \%$ levels, respectively

Bold and "Bold Italic" denote the regression coefficients for the days of the week that give the highest and lowest mean daily returns, respectively. Note that

in Panel (b) only the coefficients that give the lowest mean daily returns have been marked in bold italic.

\# The trading week for Egypt runs from Sunday to Thursday such that Monday in the table refers to Sunday, Tuesday to Monday, Wednesday to Tuesday, etc. on the Egyptian Stock Exchange

The results indicate that Mondays give the lowest mean daily returns for Botswana's Foreign Companies Index (FCI) and the All Companies Index (ACI), and for Zimbabwe's Industrial and Mining indices, consistent with the literature. However, only the Monday returns for the FCI are significant at the 5\% level. The lowest mean daily returns are observed on a Tuesday for Mauritius' SEMTRI, Morocco's CFG25, Namibia's Local Index, and Tunisia's BVMT and TUNINDEX, consistent with evidence from the Australian and Asian markets (e.g. Jaffe and Westerfield, 1985; Kim, 1988; Aggarwal and Rivoli, 1989; Ziemba,
1993; Dubois and Louvet, 1996). For the Egyptian Financial Group Index (EFGI) and the Hermes Financial Index (HFI), the lowest mean daily returns are observed on the third trading day of the week, that is, on a Tuesday according to the trading week for the Egyptian Stock Exchange which runs from Sunday to Thursday. ${ }^{1}$ For the remaining indices, ${ }^{1}$ For the Egyptian Stock Exchange, the dummy variables for the day-
of-the-week effects are used in such a way that they refer to the
previous calendar day. For example, $\mathrm{Mon}_{t}$ refers to Sunday, $\mathrm{Tue}_{t}$ to 
that is, the BRVM-Composite and BRVM-10 indices, Botswana's Domestic Companies Index (DCI), Mauritius' SEMDEX, and Namibia's Overall Index, the lowest mean daily returns fall on a Thursday. However, none of the lowest mean daily returns are observed on a Friday for all the indices.

The largest mean daily returns are observed on a Friday for the FCI and ACI (significant at the 1\% level), Zimbabwe's Mining Index, Egypt's HFI and EFGI ${ }^{2}$, and Mauritius' SEMTRI and SEMDEX. Although not all of them are significant, the evidence support the literature that Fridays offer the highest mean daily returns as compared to the other days of the week. For the other indices, the highest mean daily returns are observed on Monday for the BRVMComposite, Tuesday for the BRVM-10, Wednesday for Botswana's DCI, Namibia's Overall and Local indices, the BVMT and Zimbabwe's Industrial Index, and on a Thursday for the TUNINDEX and Morocco's CFG25 (significant at the $1 \%$ level). For the CFG25, Wednesday and Friday also provide positive and significant mean daily returns. The mean daily returns for the FCI and ACI are also positive and significant on a Wednesday.

In Panel (b) of Table 2, a significant Monday effect is observed for the ACI, FCI and CFG25 indices. A Monday effect (but not significant at the $5 \%$ level) is also observed for all the other indices, except, the BRVM-Composite, Namibia's Local Index and the TUNINDEX. The rest-ofthe-week (ROW) mean daily returns are significantly positive for the DCI, the SEMTRI, and Zimbabwe's Industrial Index.

\section{End/Turn-of-the-Month Effect}

The end-of-the-month (EOM) refers to the last trading day of the month while the turn-of-the-month (TOM) refers to the last trading day of the previous month plus the first four trading days of the current month. These five consecutive trading days are hypothesised to distinctly outperform the rest of the month (Merrill, 1966) due to investors' tendency to operate on a monthly fiscal basis (Hirsch, 1986). Merrill (1966) suggested that buying for profit before the last 3 days of the month and selling after the first 3 days of the month could be profitable. The turn-of-the-month effect is examined in this study using the following regression analysis:

$$
R_{t}=\beta_{0}+\beta_{1} \mathrm{EOMN1}_{t}+\sum_{i=1}^{4} \beta_{i+1} \mathrm{EOMPi}_{t}+\varepsilon_{t} \ldots
$$

where the constant $\beta_{0}$ represent the mean daily return for all the other days of the month, $\beta_{1}$ is the response coefficient for the dummy variable $E O M N_{t}$ that takes the value of 1 on the last day of the previous month and 0 otherwise, $\beta_{i+1}$ is the response coefficient for the dummy

Monday, $W d_{t}$ for Tuesday, and so forth. This is because trading on this stock exchange runs from Sunday to Thursday.

\footnotetext{
${ }^{2}$ Literally, on a Thursday according to the trading week for the

Egyptian Stock Exchange which runs from Sunday to Thursday.
}

variable $E O M P i_{t}$ that takes the value of 1 on the $i^{\text {th }}$ day of the current month and 0 otherwise. The null hypothesis is to test that there are no differences between mean returns for each of the turn-of-the-month days and all the other days of the month. The results of this regression model are presented in Panel (a) of Table 3.

The TOM effect is further investigated using a regression equation with one dummy explanatory variable taking the value of 1 on each of the TOM days and 0 otherwise. This regression equation is specified as follows:

$$
R_{t}=\alpha_{0}+\alpha_{1} \mathrm{TOM}_{t}+e_{t}
$$

where the constant $\alpha_{0}$ represent the mean daily returns for all the other days of the month that are not TOM and $\alpha_{1}$ is the response coefficient for the dummy variable $T O M_{t}$ that takes the value of 1 on a TOM day and 0 otherwise. The estimated coefficients for this equation are presented in Panel (b) and (c) of Table 3. The results in Panel (c) are the TOM effects after extracting the January TOM/turn-of-theyear (TOY) effect.

As shown in Panel (a) of Table 3, none of the markets have significant EOM effects. However, most of the indices exhibit positive mean-daily returns for the EOM, except for Botswana's DCI, Namibia's Local Index and Tunisia's BVMT. The EOM mean daily returns are highest only for the BRVM-10, BRVM-Composite and the GSE Index and lowest for the BVMT. The EOM effect is, therefore, very weak on the African markets. Of the TOM days, significantly positive mean daily returns (at the 5\% level) are observed only on Botswana's FCI and ACI on the second trading day of the month and on Mauritius's SEMTRI on the fourth trading day of the month. For Morocco's CFG25, the first day of the month provided significantly negative (at the 1\% level) mean daily returns. The other days of the month seem to significantly explain the mean daily returns for Botswana's DCI, the Ghana Index and Zimbabwe's Industrial Index (positive at the 1\% level), and for Egypt's HFI and EFGI (negative at the 5\% level).

The TOM analysis in Panel (b) of Table 3, suggests a significant TOM effect for Botswana's FCI and ACI (at the $1 \%$ level), Egypt's HFI and EFGI, and Mauritius's SEMDEX and SEMTRI (at the 5\% level). No significant TOM effect is observed for the BRVM, Ghana, Morocco and Tunisia's BVMT. For Namibia's Local Index, the TOM seems to give the highest, but not significant, mean daily return. After extracting the TOY effect from the series, the TOM effect remains significant for Botswana's FCI and ACI, but becomes insignificant for all the other markets (see Table 3 Panel (c)). The results, therefore, suggest that apart from Botswana, the TOM effect observed on the other markets is driven by the TOY effect. 


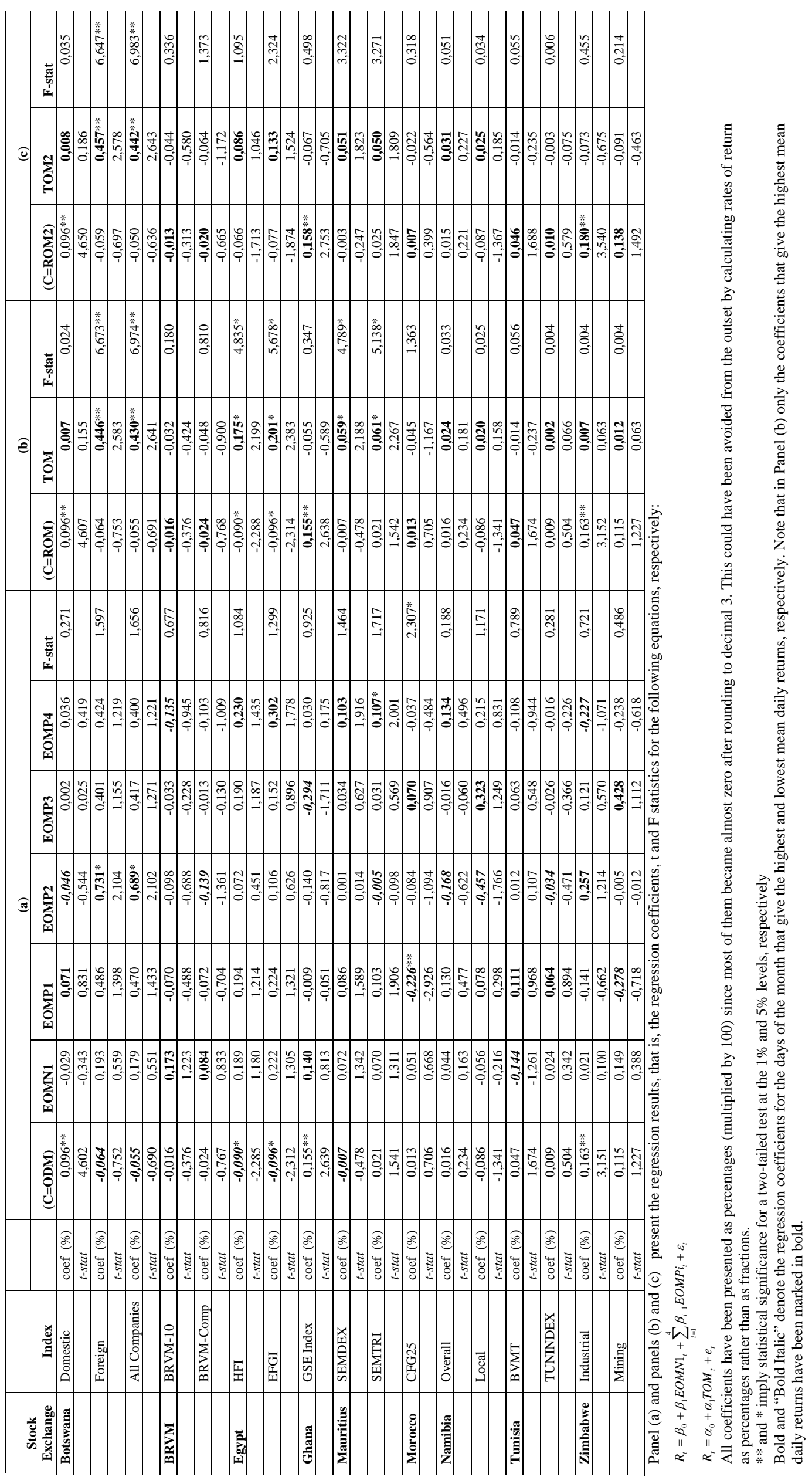




\section{End/turn-of-the-year effect}

The pattern suggested by the January effect is that stock returns are, on average, higher in the first few trading days of the year ranging from about four to ten trading days in January. The end-of-the-year (EOY) effect refers to the last trading day of the year while turn-of-the-year (TOY) effect refers to the last trading day of the year plus the first four trading days in January. In this study, the EOY/TOY effects are examined using regression equations similar to those used for the EOM/TOM effects, with the only difference being the definitions of the dummy variables. The effects are examined using the following regression equation:

$R_{t}=\beta_{0}+\beta_{1} J A N N 1_{t}+\sum_{i=1}^{4} \beta_{i+1} J A N P i_{t}+\varepsilon_{t}$

where the constant $\beta_{0}$ represent mean daily return for all the other days of the year, $\beta_{1}$ is the coefficient of the dummy variable $J A N N 1_{t}$ that takes the value of 1 on the last day of the previous year and 0 otherwise, $\beta_{i+1}$ is a coefficient for the dummy variable $J A N P i_{t}$ that takes the value of 1 on the $i^{\text {th }}$ day in January and 0 otherwise. The null hypothesis is to test that there are no differences between the mean daily returns for each of the TOY days and all the other days of the year. The results of this regression model are presented in Panel (a) of Table 4.

The TOY effect is further investigated using a regression equation with one dummy explanatory variable, $T O Y_{t}$, that takes the value of 1 on each of the TOY days and 0 otherwise, specified as follows:

$R_{t}=\alpha_{0}+\alpha_{1} T O Y_{t}+e_{t}$

where the constant $\alpha_{0}$ is the mean daily return for all the non-TOY days and $\alpha_{1}$ is the response coefficient for the dummy variable $T O Y_{t}$. The results for this equation are presented in Panel (b) of Table 4.

A significant EOY effect is observed on the BRVM's two indices, the BRVM-10 and the BRVM-Composite, and on Zimbabwe's Mining Index. In both cases the coefficients are significant at the $1 \%$ level suggesting a strong EOY effect for these indices on the two markets. For the other TOY days, the highest and significantly positive (at the $1 \%$ level) mean daily returns are observed on the first trading day in January for Egypt's HFI and EFGI Indices, and on the third trading day in January for Namibia's Local Index. Namibia's Local Index, however, exhibits the lowest and significantly negative mean daily return on the second trading day in January. Morocco's CFG25 also has the lowest and significantly negative mean daily return on the first trading day in January.

Panel (b) of Table 4 confirms the TOY effect for Egypt's two indices at the $1 \%$ level. Zimbabwe's Industrial Index also exhibits the TOY effect at the 5\% level, using regression equation (6) but the Mining Index cease to be significant. Weak TOY effects are also observed on other indices but they are not significant. Therefore, of all the indices in this analysis, only the Egyptian indices and Zimbabwe's Industrial Index seem to have strong TOY effects.

\section{Month-of-the-Year Effect}

With the month-of-the-year (MOY) effect, evidence from the US markets (see Cataldo and Savage, 2000) suggests that the three-month sequence, November, December and January provide the most favourable mean daily returns. Another MOY related hypothesis is the 'December decline followed by January rise' sequence observed on some markets ${ }^{3}$. To examine the MOY effect using regression analysis, the following model is estimated:

$$
\begin{aligned}
& R_{t}=\beta_{1}+\beta_{2} \mathrm{Feb}_{t}+\beta_{3} \mathrm{Mar}_{t}+\beta_{4} \mathrm{Apr}_{t}+\beta_{5} \mathrm{May}_{t}+\ldots+ \\
& \beta_{12} \mathrm{Dec}_{t}+\varepsilon_{t}
\end{aligned}
$$

where the constant $\beta_{1}$ represent the January mean daily return, $\beta_{2}$ is the response coefficient of the dummy variable $\mathrm{Feb}_{t}$ that takes the value of 1 in February and 0 otherwise, $\beta_{3}$ is the response coefficient for the dummy variable $\mathrm{Mar}_{t}$ that takes the value of 1 in March and 0 otherwise, and so forth. The null hypothesis is that no differences exist between the mean returns for each month of the year. The results are presented in Panel (a) of Table 5.

The literature suggests that January provides the highest and significantly positive mean daily returns compared to the other months of the year. To further examine if January provides significantly higher returns than all the other months of the year, a simplified, one dummy variable regression model is used. This is formulated as follows:

$R_{t}=\alpha_{0}+\alpha_{1} \operatorname{Jan}_{t}+e_{t}$

where the constant $\alpha_{0}$ represent mean returns for all the other months of the year and $\alpha_{1}$ is the response coefficient for the dummy variable $\mathrm{Jan}_{t}$ that takes the value of 1 in January and 0 otherwise. The estimated coefficients for this equation are presented in Panel (b) of Table 5.

\footnotetext{
${ }^{3}$ The hypothesis also suggests that the decline in December takes place in the last few days of the month, and the rise in January take place in the first few days in January.
} 
Table 4: Regression results for end/turn-of-the-year effect

\begin{tabular}{|c|c|c|c|c|c|c|c|c|c|c|c|c|}
\hline \multirow{2}{*}{$\begin{array}{l}\text { Stock } \\
\text { Exchange }\end{array}$} & \multirow[b]{2}{*}{ Index } & & \multicolumn{7}{|c|}{ (a) } & \multicolumn{3}{|c|}{ (b) } \\
\hline & & & $(\mathrm{Ct}=\mathrm{ODY} 2)$ & JANN1 & JANP1 & JANP2 & JANP3 & JANP4 & F-stat & $(\mathrm{C}=\mathrm{ROY})$ & TOY & F-stat \\
\hline \multirow[t]{6}{*}{ Botswana } & Domestic & coef $(\%)$ & $0,098^{* *}$ & 0,264 & $-0,015$ & $-0,039$ & $-0,241$ & $-0,097$ & 0,322 & 0,098** & $-0,012$ & 0,007 \\
\hline & & t-stat & 5,340 & 0,945 & $-0,047$ & $-0,125$ & $-0,772$ & $-0,311$ & & 5,346 & $-0,086$ & \\
\hline & Foreign & coef $(\%)$ & 0,042 & $-1,063$ & $-0,042$ & 1,128 & $-0,628$ & 1,560 & 0,679 & 0,042 & 0,131 & 0,055 \\
\hline & & t-stat & 0,560 & $-0,931$ & $-0,033$ & 0,884 & $-0,492$ & 1,222 & & 0,560 & 0,234 & \\
\hline & All Companies & coef (\%) & 0,047 & $-1,001$ & $-0,043$ & 1,071 & $-0,613$ & 1,441 & 0,671 & 0,047 & 0,115 & 0,047 \\
\hline & & t-stat & 0,664 & $-0,929$ & $-0,036$ & 0,889 & $-0,509$ & 1,196 & & 0,665 & 0,217 & \\
\hline \multirow[t]{4}{*}{ BRVM } & BRVM-10 & coef $(\%)$ & $-0,030$ & $1,192 * *$ & 0,121 & $-0,143$ & $-0,550$ & $-0,454$ & 1,983 & $-0,030$ & 0,088 & 0,169 \\
\hline & & t-stat & $-0,829$ & 2,746 & 0,250 & $-0,294$ & $-1,135$ & $-0,936$ & & $-0,826$ & 0,411 & \\
\hline & BRVM-Comp & coef $(\%)$ & $-0,043$ & $1,099 * *$ & 0,042 & $-0,125$ & $-0,369$ & $-0,353$ & $3,026^{* *}$ & $-0,043$ & 0,108 & 0,499 \\
\hline & & t-stat & $-1,699$ & 3,564 & 0,121 & $-0,363$ & $-1,070$ & $-1,026$ & & $-1,687$ & 0,706 & \\
\hline \multirow[t]{4}{*}{ Egypt } & HFI & coef (\%) & $-0,065$ & 0,795 & $1,552^{* *}$ & 0,780 & $1,153^{*}$ & 0,093 & $3,423^{* *}$ & $-0,065$ & $\mathbf{0 , 8 7 5 * *}$ & $13,060^{* *}$ \\
\hline & & t-stat & $-1,888$ & 1,482 & 2,891 & 1,452 & 2,149 & 0,173 & & $-1,888$ & 3,614 & \\
\hline & EFGI & coef (\%) & $-0,062$ & 0,926 & $1,470 * *$ & 0,641 & 0,822 & $-0,320$ & 2,566* & $-0,062$ & 0,708** & $7,570 * *$ \\
\hline & & t-stat & $-1,691$ & 1,623 & 2,577 & 1,124 & 1,441 & $-0,561$ & & $-1,690$ & 2,751 & \\
\hline \multirow[t]{2}{*}{ Ghana } & GSE Index & coef (\%) & $0,131 * *$ & 0,747 & $-0,009$ & $-0,085$ & $-0,123$ & $-0,167$ & 0,387 & $0,131 * *$ & 0,076 & 0,086 \\
\hline & & t-stat & 2,816 & 1,328 & $-0,014$ & $-0,150$ & $-0,218$ & $-0,297$ & & 2,820 & 0,294 & \\
\hline \multirow[t]{4}{*}{ Mauritius } & SEMDEX & coef (\%) & 0,006 & $-0,033$ & $-0,012$ & 0,124 & 0,182 & 0,247 & 0,674 & 0,006 & 0,105 & 1,622 \\
\hline & & t-stat & 0,538 & $-0,184$ & $-0,060$ & 0,686 & 1,008 & 1,365 & & 0,538 & 1,273 & \\
\hline & SEMTRI & coef (\%) & $0,034 * *$ & 0,131 & $-0,021$ & 0,123 & 0,155 & 0,230 & 0,667 & $0,034^{* *}$ & 0,129 & 2,419 \\
\hline & & t-stat & 2,856 & 0,726 & $-0,108$ & 0,680 & 0,861 & 1,275 & & 2,859 & 1,555 & \\
\hline \multirow[t]{2}{*}{ Morocco } & CFG25 & coef $(\%)$ & 0,007 & $-0,359$ & $-0,624^{*}$ & $-0,223$ & 0,121 & $-0,121$ & 1,578 & 0,007 & $-0,228$ & 3,685 \\
\hline & & t-stat & 0,418 & $-1,384$ & $-2,200$ & $-0,860$ & 0,468 & $-0,469$ & & 0,418 & $-1,920$ & \\
\hline \multirow[t]{4}{*}{ Namibia } & Overall & coef (\%) & 0,023 & 0,931 & $-0,096$ & $-0,836$ & $-0,394$ & 0,135 & 0,425 & 0,023 & $-0,051$ & 0,015 \\
\hline & & $t$-stat & 0,386 & 1,024 & $-0,096$ & $-0,921$ & $-0,433$ & 0,148 & & 0,387 & $-0,122$ & \\
\hline & Local & coef (\%) & $-0,081$ & 1,001 & $-0,461$ & $-5,054 * *$ & $4,327 * *$ & $-0,017$ & $12,500 * *$ & $-0,081$ & $-0,026$ & 0,004 \\
\hline & & t-stat & $-1,458$ & 1,171 & $-0,493$ & $-5,914$ & 5,064 & $-0,019$ & & $-1,430$ & $-0,065$ & \\
\hline \multirow[t]{4}{*}{ Tunisia } & BVMT & coef (\%) & 0,043 & $-0,141$ & $-0,181$ & $-0,050$ & 0,011 & 0,301 & 0,189 & 0,043 & $-0,005$ & 0,001 \\
\hline & & $t$-stat & 1,771 & $-0,366$ & $-0,422$ & $-0,129$ & 0,028 & 0,783 & & 1,773 & $-0,028$ & \\
\hline & TUNINDEX & coef (\%) & 0,008 & 0,145 & $-0,090$ & $-0,108$ & $-0,086$ & 0,350 & 0,588 & 0,008 & 0,048 & 0,188 \\
\hline & & t-stat & 0,549 & 0,605 & $-0,334$ & $-0,451$ & $-0,356$ & 1,457 & & 0,549 & 0,433 & \\
\hline \multirow[t]{4}{*}{ Zimbabwe } & Industrial & coef $(\%)$ & $0,150^{* *}$ & 1,219 & 1,057 & 1,356 & 0,138 & $-0,085$ & 1,680 & $0,150 * *$ & 0,726* & $4,960 *$ \\
\hline & & t-stat & 3,309 & 1,713 & 1,357 & 1,907 & 0,194 & $-0,119$ & & 3,310 & 2,227 & \\
\hline & Mining & coef (\%) & 0,100 & $4,044^{* *}$ & 1,580 & $-0,223$ & $-0,305$ & $-0,274$ & $2,233 *$ & 0,100 & 0,943 & 2,528 \\
\hline & & $t$-stat & 1,211 & 3,130 & 1,116 & $-0,173$ & $-0,236$ & $-0,212$ & & 1,209 & 1,590 & \\
\hline
\end{tabular}

Panel (a) and panel (b) present the regression results, that is, the regression coefficients, $\mathrm{t}$ and $\mathrm{F}$ statistics for the following equations, respectively:

$R_{t}=\beta_{0}+\beta_{1} J A N N 1_{t}+\sum_{i=1}^{4} \beta_{i 1} J A N P i_{t}+\varepsilon_{t}$

$R_{t}=\alpha_{0}+\alpha_{1} T O Y_{t}+e_{t}$

All coefficients have been presented as percentages (multiplied by 100) since most of them became almost zero after rounding to decimal 3 This could have been avoided from the outset by calculating rates of return as percentages rather than as fractions

** and * imply statistical significance for a two-tailed test at the $1 \%$ and $5 \%$ levels, respectively

Bold and "Bold Italic" denote the regression coefficients for the days of the year that give the highest and lowest mean daily returns, respectively Note that in Panel (b) only the coefficients that give the highest mean daily returns have been marked in bold

From the results in Panel (a) of Table 5, January seems to give significantly positive mean daily returns for Egypt's HFI and EFGI indices, Mauritius' SEMDEX and SEMTRI, Tunisia's BVMT and TUNINDEX, and for Zimbabwe's Industrial Index. Although most of the indices, except the BRVM-10, BRVM-Composite and Namibia's Local Index, have negative coefficients for the December dummy, none of them are significant, except for the TUNINDEX (at the $5 \%$ level) and Zimbabwe's Industrial index (at the 1\% level). All the indices have at least one significant coefficient, except for Botswana's FCI and ACI, Namibia's Local Index and Zimbabwe's Mining Index, suggesting the absence of the MOY effect for these indices. The BRVM's two indices exhibit a reversed 'December decline followed by January rise' pattern. The other significant coefficients for the BRVM are for the months of May, September and October, and they are all positive. Other indices exhibiting significantly positive mean daily returns in months other than January are Botswana's DCI and Morocco's CFG25 (highest in August), and the GSE Index (highest in April). For all the other indices, the significant coefficients for the months February to November are all negative.
The results described above, and those in Panel (b) of Table 5 , suggest the presence of a significant January effect in the Egyptian indices, Mauritius, Tunisia and Zimbabwe's Industrial Index. January provides the highest (but not significant) mean daily returns for Botswana's FCI and ACI, Morocco's CFG25 and Namibia's Overall and Local Indices. A significantly negative January effect is observed for the BRVM indices. 


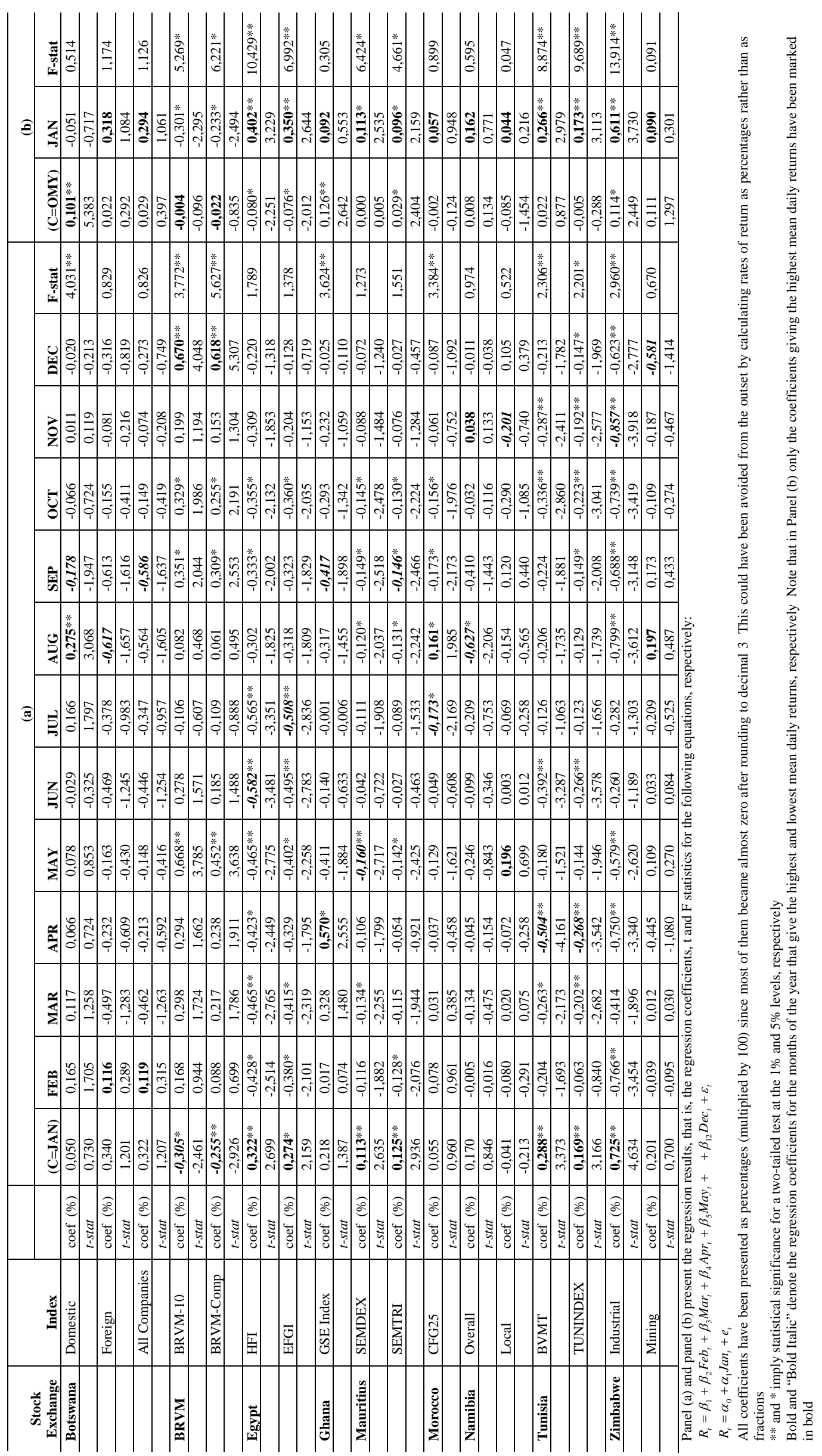




\section{Week-of-the-month effect}

In this study, the week-of-the-month (WOM) effect is defined as in Roux and Smit (2001) in which the first trading week of the month consists of the first five trading days of the month, the second and third trading weeks consist of the sixth to the tenth, and the eleventh to fifteenth, trading days of the month, respectively. All the remaining days of the month are classified as week 4 . The WOM effect is defined differently only for Ghana. Since the market was trading only three times a week for the period under investigation, the first trading week of the month is defined as the first three trading days of the month, the second week as the fourth to the sixth trading day of the month, and so forth. To examine the WOM effect using regression analysis, the following equation is estimated:

$$
R_{t}=\beta_{1}+\sum_{i=2}^{4} \beta_{i} W K i_{t}+\varepsilon_{t}
$$

where the constant $\beta_{1}$ represent the mean return for week 1 , $\beta_{i}$ is the response coefficient for the dummy variable $W K i_{t}$ that takes the value of 1 in week $i$ and 0 otherwise, for $i=2,3$ and 4 . The null hypothesis is that there are no differences in the mean returns for each week of the month. The results of this regression model are presented in Table 6.

The results in Table 6 suggest that there are no strong weekof-the-month effects on the African stock markets studied. The only significant coefficients observed are the week 1 mean returns for Botswana's DCI and Zimbabwe's Industrial index (positive at the $5 \%$ level of significance), the week 3 mean daily returns for Egypt's HFI and EFGI, and the week 4 mean daily returns for Botswana's FCI and ACI (negative at the $1 \%$ and $5 \%$ levels of significance, respectively). Although not significant, week 1 provides the largest mean daily returns for Botswana's FCI and ACI, Egypt's HFI and EFGI, and Zimbabwe's Industrial Index. The mean daily returns are highest in week 2 for the GSE Index, the CFG25, and Namibia's Overall Index, and in week 3 for Botswana's DCI, Mauritius's SEMTRI and SEMDEX, Namibia's Local Index, and Tunisia's BVMT. The mean daily returns are highest in week 4 for both of the BVRM indices, the TUNINDEX and Zimbabwe's Mining Index. Considering the F-statistic, only the BRVM and Egypt have significant WOM effects.

Table 6: Regression Results for Week-of-the-Month Effect

\begin{tabular}{|c|c|c|c|c|c|c|c|}
\hline Stock Exchange & Index & & $(\mathrm{C}=\mathrm{WK} 1)$ & WK2 & WK3 & WK4 & F-stat \\
\hline \multirow[t]{6}{*}{ Botswana } & Domestic & coef. (\%) & 0,094* & $-0,014$ & 0,023 & 0,005 & 0,176 \\
\hline & & t-stat & 2,552 & $-0,278$ & 0,440 & 0,104 & \\
\hline & Foreign & coef. (\%) & 0,264 & $-0,161$ & $-0,270$ & $-0,422^{*}$ & 1,473 \\
\hline & & $t$-stat & 1,752 & $-0,756$ & $-1,268$ & $-2,039$ & \\
\hline & All Companies & coef. (\%) & 0,263 & $-0,161$ & $-0,261$ & $-0,407 *$ & 1,528 \\
\hline & & $t$-stat & 1,846 & $-0,802$ & $-1,301$ & $-2,083$ & \\
\hline \multirow[t]{4}{*}{ BRVM } & BRVM-10 & coef. (\%) & $-0,068$ & $-0,103$ & 0,081 & 0,167 & $2,731^{*}$ \\
\hline & & $t$-stat & $-0,946$ & $-1,011$ & 0,795 & 1,696 & \\
\hline & BRVM-Comp & coef. (\%) & $-0,087$ & $-0,051$ & 0,107 & 0,121 & $2,760 *$ \\
\hline & & $t$-stat & $-1,697$ & $-0,704$ & 1,485 & 1,714 & \\
\hline \multirow[t]{4}{*}{ Egypt } & HFI & coef. (\%) & 0,073 & $-0,038$ & $-0,265^{* *}$ & $-0,170$ & $3,113^{*}$ \\
\hline & & $t$-stat & 1,053 & $-0,392$ & $-2,700$ & $-1,795$ & \\
\hline & EFGI & coef. (\%) & 0,093 & $-0,075$ & $-0,294 * *$ & $-0,186$ & $3,067^{*}$ \\
\hline & & $t$-stat & 1,263 & $-0,721$ & $-2,820$ & $-1,849$ & \\
\hline \multirow[t]{2}{*}{ Ghana } & GSE Index & coef. (\%) & 0,006 & 0,206 & 0,099 & 0,191 & 1,073 \\
\hline & & $t$-stat & 0,067 & 1,562 & 0,752 & 1,508 & \\
\hline \multirow[t]{4}{*}{ Mauritius } & SEMDEX & coef. (\%) & 0,019 & $-0,043$ & 0,024 & $-0,023$ & 1,455 \\
\hline & & $t$-stat & 0,809 & $-1,264$ & 0,710 & $-0,689$ & \\
\hline & SEMTRI & coef. (\%) & 0,046 & $-0,037$ & 0,027 & $-0,026$ & 1,437 \\
\hline & & $t$-stat & 1,940 & $-1,087$ & 0,792 & $-0,805$ & \\
\hline \multirow[t]{2}{*}{ Morocco } & CFG25 & coef. (\%) & $-0,037$ & 0,064 & 0,048 & 0,047 & 0,690 \\
\hline & & $t$-stat & $-1,122$ & 1,364 & 1,009 & 1,022 & \\
\hline \multirow[t]{4}{*}{ Namibia } & Overall & coef. (\%) & 0,045 & 0,027 & $-0,004$ & $-0,110$ & 0,278 \\
\hline & & $t$-stat & 0,382 & 0,164 & $-0,023$ & $-0,674$ & \\
\hline & Local & coef. (\%) & $-0,137$ & $-0,017$ & $\mathbf{0 , 1 2 0}$ & 0,119 & 0,440 \\
\hline & & $t$-stat & $-1,222$ & $-0,107$ & 0,752 & 0,759 & \\
\hline \multirow[t]{4}{*}{ Tunisia } & BVMT & coef. (\%) & 0,056 & $-0,014$ & 0,030 & $-0,058$ & 0,601 \\
\hline & & $t$-stat & 1,126 & $-0,198$ & 0,430 & $-0,864$ & \\
\hline & TUNINDEX & coef. (\%) & 0,005 & $-0,005$ & 0,009 & 0,014 & 0,076 \\
\hline & & $t$-stat & 0,147 & $-0,106$ & 0,194 & 0,325 & \\
\hline \multirow[t]{4}{*}{ Zimbabwe } & Industrial & coef. (\%) & 0,199* & $-0,021$ & $-0,118$ & $-0,007$ & 0,365 \\
\hline & & $t$-stat & 2,171 & $-0,164$ & $-0,908$ & $-0,052$ & \\
\hline & Mining & coef. (\%) & 0,222 & $-0,147$ & $-0,295$ & 0,008 & 0,763 \\
\hline & & t-stat & 1,329 & $-0,622$ & $-1,249$ & 0,037 & \\
\hline
\end{tabular}

The table presents the regression results, that is, the regression coefficients, $\mathrm{t}$ and $\mathrm{F}$ statistics for the equation: $R_{t}=\beta_{1}+\sum_{i=2}^{4} \beta_{i} W K_{t}+\varepsilon_{t}$

All coefficients have been presented as percentages (multiplied by 100) since most of them became almost zero after rounding to decimal 3 . This could have been avoided from the outset by calculating rates of return as percentages rather than as fractions.

** and * imply statistical significance for a two-tailed test at the $1 \%$ and $5 \%$ levels, respectively

Bold denotes the regression coefficient for the week of the month that gives the highest mean daily return. 


\section{Kruskal-Wallis and Chi-square median tests}

The regression results are substantiated with results from the more robust Kruskal-Wallis and Chi-square Median tests. The Kruskal-Wallis and Median tests for the TOM and TOY effects emulate those for the regression equations that make use of only one dummy explanatory variable.

The results (presented in Table 7) suggest a significant DOW effect for Botwana's FCI and ACI, Morrocco's CFG25 and Zimbabwe's Industrial index, using the KruskalWallis test. In addition to these indices, Egypt's HFI and EFGI also exhibit significant DOW effects, using the ChiSquare Median test. Significant TOM effects are only observed on Egypt's HFI and EFGI, using the KruskalWallis test, and only on the EFGI, using the Chi-square Median test. When the TOY effect is extracted from the return series, the TOM effect observed in the Egyptian indices disappears. This tends to indicate that the observed TOM effect is in actual fact a TOY effect. The two Egyptian indices are also the only indices with significant WOM effects, observed using the Kruskal-Wallis but not with the Chi-square Median test.

Interestingly, even with such robust tests, the TOY and the MOY effects persist on some indices. A significant TOY effect is observed on Egypt's HFI and EFGI, and on Zimbabwe's Industrial index using both nonparametric tests. The TOY effect is also observed on Mauritius' SEMTRI and SEMDEX using the Kruskal-Wallis and the Chi-square Median tests, respectively. The relatively more persistent seasonality is the MOY effect. This is observed on Botswana's DCI, the BRVM-10 and BRVM-Composite, the GSE Index, the CFG25 and Zimbabwe's Industrial Index, using both nonparametric tests, and on Tunisia's BVMT and Zimbabwe's Mining Index, using the Kruskal-Wallis and Chi-square Median tests, respectively.

\section{Summary and concluding remarks}

Stock market seasonal effects on seventeen indices from nine African stock markets are investigated. Using regression analysis, significant Monday effects are found on two of Botswana's indices, the FCI and the ACI, and on Morocco's CFG25. Significant TOM effects are also found on the FCI and ACI, and on the Egyptian and Mauritian indices, using regression analysis. The TOM effects disappeared for Egypt and Mauritius after removing the
TOY effects, suggesting that the TOM effects on these markets could be TOY effects. However, the TOY effects are significant only for Egypt and Zimbabwe's Industrial Index, but not for Mauritius. Significant MOY effects were observed on the BRVM, Morocco, Tunisia, Ghana, Botswana's Domestic Index and Zimbabwe's Industrial Index. A reversed December/January pattern was observed for the BRVM to indicate the highest mean daily returns in December and the lowest mean daily returns in January. For Egypt, Mauritius, Tunisia and Zimbabwe's Industrial Index, January provides the highest, positive and significant mean daily returns as compared to all the other months of the year. Significant WOM effects are evident only for the BRVM and Egyptian indices.

The seasonal effects are almost just as strong using the nonparametric Kruskal-Wallis and Chi-square Median tests except the TOM and WOM effects in which the effects are only significant for the Egyptian indices. In addition to the markets exhibiting significant effects under the regression analysis method, Egypt and Zimbabwe's Industrial Index also exhibit significant DOW effects using the Chi-square Median test. Significant TOY effects are also observed on Mauritius' SEMDEX and SEMTRI using the Chi-square Median and Kruskal-Wallis tests respectively. The MOY effects, observed using regression analysis, are confirmed on most indices using the Kruskal-Wallis test.

While the indices for most markets exhibit at least one seasonal effect, no significant seasonal effects are observed for the Namibian indices using the nonparametric tests. On the other markets, the presence of these predictable seasonal patterns seems to suggest exploitable trading opportunities.

This study only presented the evidence on the existence of seasonal patterns on African stock markets. It is also important to investigate the dynamics of these patterns on African stock markets. While the weekend effect is said to have disappeared or been reversed for the U.S. market, it would be important to investigate whether the seasonal patterns observed in this study are persistent or only specific to the periods investigated. It would also be interesting to investigate if seasonal patterns exist on African stock markets for the same reasons they exist on stock markets elsewhere. Such an investigation might reveal new factors that are specific only to African stock markets. These, and other issues, shall be covered in a follow-up study. 


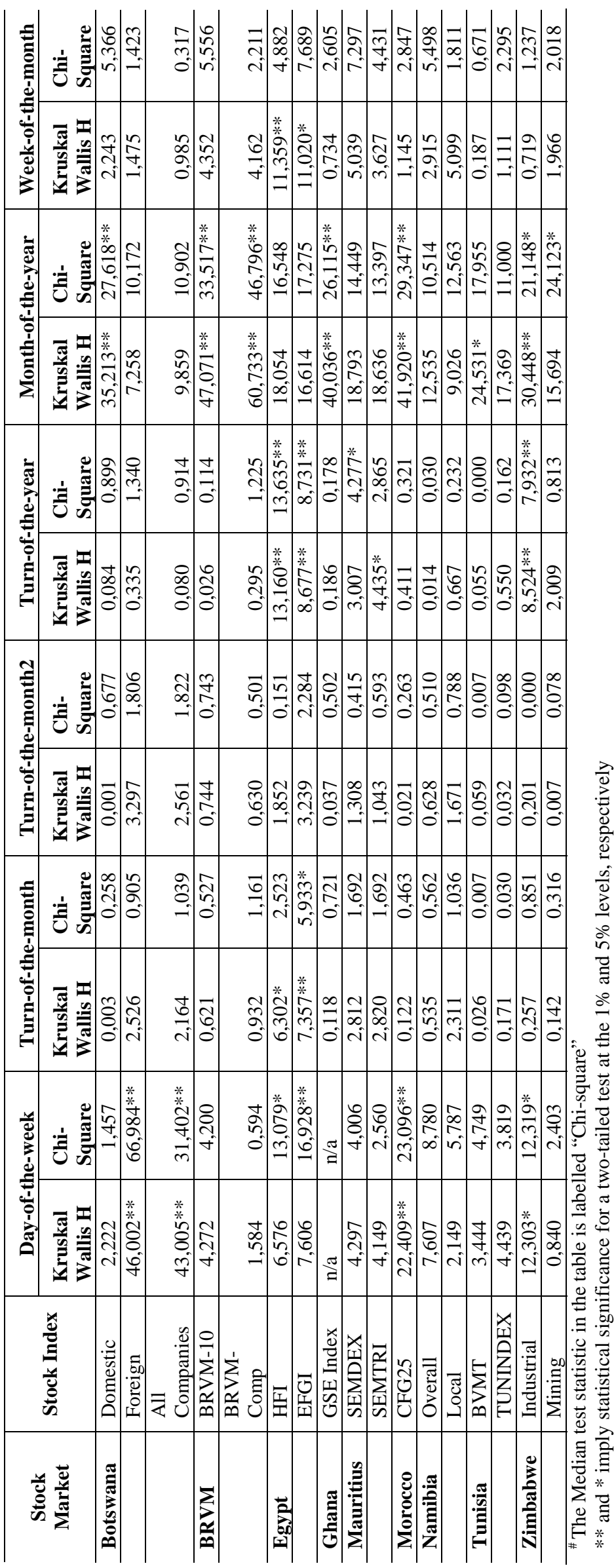




\section{References}

Aggarwal, R. \& Rivoli, P. 1989. 'Seasonal and day-of-theweek effects in four emerging stock markets', The Financial Review, 24:541-550.

Ayadi, O. F., Dufrene, U. B. \& Chatterjee, A. 1998. 'Stock return seasonalities in low-income African emerging markets', Managerial Finance Journal, 24(3):22-33.

Bhana, N. 1985. 'The Monday effect on the Johannesburg Stock Exchange', South African Journal of Business Management, 16:7-11.

Bhana, N. 1994. 'Public holiday share price behaviour on the Johannesburg Stock Exchange', Investment Analysts Journal, 39:45-49.

Bradfield, D. J. 1990. 'A note on the seasonality of stock returns on the Johannesburg Stock Exchange', South African Journal of Business Management, 21:7-9.

Cataldo, A. J. \& Savage, A. A. 2000. 'The January effect and other seasonal anomalies: A theoretical framework', Studies in Managerial and Financial Accounting, 9. Stamford, Connecticut: JAI Press.

Davidson, S. \& Meyer, S. 1993. 'The Monday effect and the Johannesburg Stock Exchange revisited', South African Journal of Business Management, 24:83-87.

Dubois, M. \& Louvet, P. 1996. 'The day-of-the-week effect: The international evidence', Journal of Banking and Finance, 20:1463-1484.

Fields, M. J. 1931. 'Stock prices: A problem in verification', The Journal of Business of the University of Chicago, 4: 677-699.

Fields, M. J. 1934. 'Security prices and stock exchange holidays in relation to short selling', The Journal of Business of the University of Chicago, 7:328-338.

Hirsch, Y. 1986. Don't sell stocks on Monday. New York: Facts on File Publications.

Jaffe, J. F. \& Westerfield, R. 1985. 'The weekend effect in common stock returns: The international evidence', The Journal of Finance, 40:433-454.

Kim, S-W. 1988. 'Capitalising on the weekend effect', The Journal of Portfolio Management, Spring:59-63.

Merrill, A. 1966. The behaviour of prices on Wall Street. Chappaqua, New York: The Analysis Press.

Roux, J. Le \& Smit, EvdM. 2001. 'Seasonal patterns on the Johannesburg Stock Exchange: Some new evidence', Studies in Economics and Econometrics, 25(1):27-61.

Wachtel, S. B. 1942. 'Certain observations on seasonal movements in stock prices', The Journal of Business of the University of Chicago, 15:184-193.
Watson, G. \& Smit, EvdM. 1994. 'Seasonal patterns in the South African share index futures market', South African Journal of Business Management, 25:155-161.

Ziemba, W. T. 1993. "Comment on "Why a Weekend Effect?”, The Journal of Portfolio Management, Winter:93-99. 